EISSN:2706-7920 ISSN: 2077-4435

DOI: $10.36632 / \mathrm{csi} / 2021.10 .4 .49$

Journal homepage: www.curresweb.com

Pages: 575-584

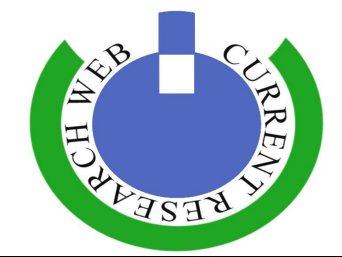

\title{
Impact of Socioeconomic Status and Dietary Habits on Seizure Control between People with Epilepsy
}

\author{
Arwa M. El-Ashry ${ }^{1}$, Thanaa A. El-Kholy ${ }^{1}$, Asmaa M. Ebraheim², and Samah A. El- \\ Hashash $^{1}$
}

${ }^{1}$ Nutrition and Food Science Dept., Faculty of Home Economics, Al-Azhar University, Egypt

${ }^{2}$ Neurology Dept., Faculty of Medicine, Cairo University, Egypt

Received: 22 Sept. $2021 \quad$ Accepted: 27 Oct. $2021 \quad$ Published: 10 Nov. 2021

\begin{abstract}
Background: All over the world, increasing interest was directed to epilepsy as one of the most prevalent neurological chronic diseases. Socioeconomic status (SES) and dietary habits play a pivotal role in epilepsy prevalence and management. Aim of study was to highlight the relationship between SES and dietary habits of patients with epilepsy and its frequency and/or control. Methods: Acrosssectional descriptive study involved 123 patients recruited by convenience from the Epilepsy Clinic of the Neurology Department at Kasr Al-Ainy Hospital, Cairo University, Egypt. The sample consisted of patients of both genders ( 80 males and 43 females) aged $\geq 18$ years, who had been diagnosed with epilepsy for at least one year. The studied variables included socio-demographic characteristics and dietary habits. Results: Results shows that two thirds of all patients $(65 \%)$ were male. Patients were aged between 18 and 65 years (mean: 30.3, SD: 10.45) and revealed statistically significant differences between subjects with controlled and uncontrolled epilepsy in both education which $(65 \%)$ They had secondary education or above in the control group and total socioeconomic levels where more than half of them $(57.8 \%)$ were low socioeconomic levels in uncontrol group. As for dietary habits shows revealed statistically significant differences between subjects with controlled and uncontrolled epilepsy in Presence of unhealthy food at home (95\%) in uncontrol group and Appetite (30\%) good appetite in control group ( $\mathrm{P}$-values $=0.007$ and 0.043 respectively), and a reverse statistically significant correlation was found between the frequency of seizures and appetite, frequency of salad eating and a number of glasses of water/day (P-values $=0.001,=0.001$ and 0.002 respectively). In contrast, frequency of seizure attacks was positively correlated with eating unhealthy food, frequency of fast food eating and consumption of sugar $(\mathrm{P}-\mathrm{values}=0.001)$ for all. According to these findings, increasing socioeconomic status level and dietary behavior modification are recommended in order to improve the health status of hospitalized patients with epilepsy.
\end{abstract}

Keywords: Food habits, Income, Education, Seizure's frequency.

\section{Introduction}

All over the world, increasing interest was directed to epilepsy as one of the most prevalent neurological chronic diseases with a prevalence of approximately 0.4 to $1 \%$; which affects people of all ages and races, and both genders (Kobow \& Blümcke, 2018; World health organization, 2019). In Egypt, the childhood and adolescence epilepsy (children $<18$ years) is 9.7/1000 (Farghaly et al., 2018). On the other hand, the estimated direct costs of epilepsy were found to be approximately $\$ 28$ billion per year, i.e. it is associated with a substantial economic burden a significant portion of which can be attributed to increases in all-cause costs related to uncontrolled epilepsy (Begley \& Durgin, 2015; Chen et al., 2013).

Physiologically, epilepsy is a condition in which a person has recurrent seizures; a seizure is defined as a disorderly, abnormal discharging of the brain's nerve cells, resulting in a temporary disturbance of sensory, motor, or mental function (Zhou \& Li, 2020). Epilepsy is considered a cause 
of many premature death circumstances and racial discrimination (Kutlu \& Mülayim, 2016; Surges \& Sander, 2012).

There is a growing body of evidence implicating socioeconomic status (SES) as a risk factor for epilepsy in adults (Heaney et al., 2002; Hesdorffer et al., 2005). Hesdorffer et al., (2005) found an association between epilepsy and SES among adults, but not among children, suggesting a cumulative effect of SES on risk for epilepsy. Socioeconomic factors may influence the risk of the disease in many ways. For example, exposure to harmful agents may be related to occupational, residential, and lifestyle factors, which may depend on SES (Frigerio et al., 2005). Generally, apart from the negative impact of disease and treatment in the epilepsy population, issues on the influence of sociodemographic characteristics such as ethnicity and income on health status are deemed crucial in current efforts to advance health outcome measurement (Olson et al., 2004).

On the other hand, quality of life impairments is common in patients with epilepsy, especially due to the high prevalence of comorbidities such as type II diabetes mellitus, hypercholesterolemia, arterial hypertension, stroke and cancer in this population (Elliot et al., 2009). Previous reports indicate that nutrition and eating habits play a pivotal role in epilepsy prevalence and management. The interaction between food and antiepileptic drugs causes many disorders such as bone diseases resulting from poor vitamin D metabolism (Ahmad et al., 2012), in addition to zinc and copper deficiency (Soltani et al., 2016), and selenium deficiency which is one of the most important antioxidants (Castro-Gago et al., 2011). In general, few studies have addressed the eating habits of patients with epilepsy (Amari et al., 2007; Dekker et al., 2010).

There is a lack of population-based data on the association between socioeconomic factors and dietary habits on a hand and epilepsy control on the other hand. So, the object of the current study was to increase insight into this association in hospitalized epileptic Egyptian patients.

\section{Subjects and Methods}

The present study was a cross-sectional descriptive trial that involved 123 patients recruited by convenience from the Epilepsy Clinic of the Neurology Department at Kasr Al Ainy Hospital, Cairo University, Egypt. The sample size was identified according to Thompson (2012). It consisted of patients of both genders ( 80 males and 43 females) aged $\geq 18$ years, who had been diagnosed with epilepsy for at least one year by a neurology physician. Before participating in the study, the protocol was fully explained to the patients and their informed consent was obtained. The following exclusion criteria were applied: pregnancy or lactation at the time of the study and presence of other neurological diseases which impaired cognitive functioning. Data were collected from June 2019 until April 2021. The study sample fulfilled the International League Against Epilepsy (ILAE) criteria of epilepsy withering controlled or uncontrolled patients (Prognosis, 1993), as a patient with epilepsy is classified as controlled if he did not have a seizure for the last 12 months(Fernandez et al., 2015). An individually face to face interview was carried out with patients and each interview took about 45-60 minutes.

Socio-demographics characteristics were evaluated by the valid and reliable socio-demographic scale for health research in Egypt.

This scale has seven domains with a total score 84 and it classifies patients into four sections including a low, low, moderate, and high level of SES. It contains information on the level of education, employment status, culture, place of residence, family property, the number of children receiving education, to what extent income meets the needs of the family, the type of government support that the patient receives (El-Gilany et al., 2012).

Dietary assessment was also done using a valid and reliable scale and questionnaire which showed a respectable reliability in assessing a patient's eating habits and identifying its attitudes towards food (Long and Shannon, 1983; Reis et al., 2019). In general, the used questionnaires were developed in a systematic multistep method according to

The obtained data were analyzed through Statistical Package for Social Sciences program (SPSS), version 22. Qualitative variables were expressed as percentages and association measures available within cross tabs are used as tests of independence between the categorical variables. $\chi^{2}$ test (chi-square) was used for comparison among proportions. Quantitative variables from normal distribution were expressed as mean $\pm \mathrm{SD}$. An independent t-test was used to compare between the two sample means and there are two assumptions underlying the analysis. The first is that the variable 
is normally distributed. The second is that the standard deviation between individuals is the same in each group. Pearson's correlation coefficient ( $\mathrm{r}$ ) has been also applied in this study between two quantities variables, while spearman correlation coefficient was applied for ordinal variables. $\mathrm{P}<0.05$ was adopted as the level of significance.

\section{Results}

According to ILAE criteria of epilepsy, about third of the participants $(32.5 \%)$ were controlled, and two thirds $(67.5 \%)$ were uncontrolled patients. The results of socio-demographic and dietary habits evaluation were as in the following tables:

\subsection{Demographic characteristics and socioeconomic level of subjects:}

Table (1) shows that two thirds of all patients (65\%) were male. Patients were aged between 18 and 65 years (mean: 30.3, SD: 10.45). More than half of all patients (54.5\%) were married, whereas $43.9 \%$ were single, and only $1.6 \%$ were divorced. Nearly half of the participants do not have offspring (50.4\%), whereas 46.3 have offspring. On the other hand, 33.3\% of participants have a secondary education and only $15.4 \%$ were graduates, versus $27.6 \%$ were illiterate. At the same time, $37.4 \%$ of study participants had current paid employment, and $35.7 \%$ were unemployed and not looking for work because of their seizures, while $26.8 \%$ were students. Almost half of the participants $(49.6 \%)$ also had a very low socioeconomic level, and $37.4 \%$ had a low socioeconomic level, while only $13 \%$ had a moderate socioeconomic level.

Table 1: Description of sociodemographic characteristics of participants

\begin{tabular}{|c|c|c|}
\hline Variables & \multicolumn{2}{|c|}{$(n=123)$} \\
\hline \multicolumn{3}{|l|}{ Age (years) } \\
\hline Mean \pm SD & \multirow{2}{*}{\multicolumn{2}{|c|}{$\begin{array}{c}30.33 \pm 10.45 \\
18.0-65.0 \\
\end{array}$}} \\
\hline \multirow[t]{2}{*}{ Range } & & \\
\hline & $\mathbf{n}$ & $\%$ \\
\hline \multicolumn{3}{|l|}{ Gender } \\
\hline Male & 80 & $65.0 \%$ \\
\hline Female & 43 & $35.0 \%$ \\
\hline \multicolumn{3}{|l|}{ Marital } \\
\hline Single & 54 & 43.9 \\
\hline Married & 67 & 54.5 \\
\hline Divorced & 2 & 1.6 \\
\hline \multicolumn{3}{|l|}{ Offspring } \\
\hline Yes & 57 & 46.3 \\
\hline Planning to & 4 & 3.3 \\
\hline No & 62 & 50.4 \\
\hline \multicolumn{3}{|l|}{ Education } \\
\hline Illiterate & 34 & 27.6 \\
\hline Read \& write & 11 & 8.9 \\
\hline Primary & 6 & 4.9 \\
\hline Preparatory & 12 & 9.8 \\
\hline Secondary & 41 & 33.3 \\
\hline University & 19 & 15.4 \\
\hline \multicolumn{3}{|l|}{ Occupation } \\
\hline Working & 46 & 37.4 \\
\hline Not working & 44 & 35.7 \\
\hline Students & 33 & 26.8 \\
\hline \multicolumn{3}{|l|}{ Socioeconomic level } \\
\hline Very low & 61 & $49.6 \%$ \\
\hline Low & 46 & $37.4 \%$ \\
\hline Moderate & 16 & $13.0 \%$ \\
\hline High & 0 & $0 \%$ \\
\hline
\end{tabular}

Table (2) points to statistically significant differences between subjects with controlled epilepsy and uncontrolled epilepsy in both education and socioeconomic levels. The level of education was 
higher in the group with controlled epilepsy than the uncontrolled group, as it was $40 \%$ for secondary education in the controlled group versus $30.1 \%$ in the uncontrolled group, and it was $25 \%$ for university education in the controlled group, while it was $10.8 \%$ in the uncontrolled group. On the other hand, the illiteracy rate in the uncontrolled group was $34.9 \%$ versus $12.5 \%$ in the controlled group. As for the socioeconomic level, it was noted that the percentage of participants with very low socioeconomic level was higher $(57.8 \%)$ in the uncontrolled group than in the controlled group $(32.5 \%)$. Conversely, the moderate level was $22.5 \%$ in the controlled group and $8.5 \%$ in the uncontrolled group. There were no statistically significant differences between participants with controlled epilepsy and those with uncontrolled epilepsy in age mean, gender, marital status, having offspring, and occupation. However, most of the participants in the uncontrolled group were females, married, and unemployed.

Table 2: Comparison between controlled epileptics and uncontrolled epileptics regarding demographic characteristics and socioeconomic level

\begin{tabular}{|c|c|c|c|c|c|c|}
\hline Age $\quad$ Variables & & & & lled & $\begin{array}{c}\text { Sig. test } \\
T\end{array}$ & $\mathbf{P}$ \\
\hline Mean \pm SD & $28.6 \pm$ & 9.5 & $31.2 \pm$ & 10.9 & -1.279 & 0.203 \\
\hline Gender & $\mathrm{n}$ & $\%$ & $\mathrm{n}$ & $\%$ & $\chi^{2}$ & \\
\hline $\begin{array}{l}\text { Males } \\
\text { Females }\end{array}$ & $\begin{array}{l}27 \\
13\end{array}$ & $\begin{array}{l}67.5 \% \\
32.5 \%\end{array}$ & $\begin{array}{l}53 \\
30\end{array}$ & $\begin{array}{l}63.9 \% \\
36.1 \%\end{array}$ & 0.158 & 0.691 \\
\hline $\begin{array}{l}\text { Marital } \\
\text { Single } \\
\text { Married } \\
\text { Divorced } \\
\end{array}$ & $\begin{array}{c}19 \\
20 \\
1 \\
\end{array}$ & $\begin{array}{c}47.5 \% \\
50.0 \% \\
2.5 \% \\
\end{array}$ & $\begin{array}{c}35 \\
47 \\
1 \\
\end{array}$ & $\begin{array}{c}42.2 \% \\
56.6 \% \\
1.2 \% \\
\end{array}$ & $\begin{array}{c}\chi^{2} \\
0.671\end{array}$ & 0.715 \\
\hline $\begin{array}{l}\text { Offspring } \\
\text { Yes } \\
\text { Planning to } \\
\text { No } \\
\end{array}$ & $\begin{array}{c}19 \\
1 \\
20\end{array}$ & $\begin{array}{c}47.5 \% \\
2.5 \% \\
50.0 \% \\
\end{array}$ & $\begin{array}{c}38 \\
3 \\
42 \\
\end{array}$ & $\begin{array}{c}45.8 \% \\
3.6 \% \\
50.6 \% \\
\end{array}$ & $\begin{array}{c}\chi^{2} \\
0.122\end{array}$ & 0.941 \\
\hline $\begin{array}{l}\text { Education } \\
\text { Illiterate } \\
\text { Read \& write } \\
\text { Primary } \\
\text { Preparatory } \\
\text { Secondary } \\
\text { University }\end{array}$ & $\begin{array}{c}5 \\
5 \\
1 \\
3 \\
16 \\
10\end{array}$ & $\begin{array}{c}12.5 \% \\
12.5 \% \\
2.5 \% \\
7.5 \% \\
40.0 \% \\
25.0 \%\end{array}$ & $\begin{array}{c}29 \\
6 \\
5 \\
9 \\
25 \\
9\end{array}$ & $\begin{array}{c}34.9 \% \\
7.2 \% \\
6.0 \% \\
10.8 \% \\
30.1 \% \\
10.8 \%\end{array}$ & $\begin{array}{c}\chi^{2} \\
11.044\end{array}$ & $0.042 *$ \\
\hline $\begin{array}{l}\text { Occupation } \\
\text { Working } \\
\text { Not working }\end{array}$ & $\begin{array}{l}16 \\
24\end{array}$ & $\begin{array}{l}40.0 \% \\
60.0 \%\end{array}$ & $\begin{array}{l}30 \\
53\end{array}$ & $\begin{array}{l}36.1 \% \\
63.9 \%\end{array}$ & $\begin{array}{c}\chi^{2} \\
0.171\end{array}$ & 0.679 \\
\hline $\begin{array}{l}\text { Socioeconomic level } \\
\text { Very low } \\
\text { Low } \\
\text { Moderate } \\
\text { High }\end{array}$ & $\begin{array}{c}13 \\
18 \\
9 \\
0\end{array}$ & $\begin{array}{c}32.5 \% \\
45.0 \% \\
22.5 \% \\
0 \%\end{array}$ & $\begin{array}{c}48 \\
28 \\
7 \\
0\end{array}$ & $\begin{array}{c}57.8 \% \\
33.7 \% \\
8.5 \% \\
0 \%\end{array}$ & $\begin{array}{c}\chi^{2} \\
7.925\end{array}$ & $0.019^{*}$ \\
\hline
\end{tabular}

* Statistically significant

\subsection{Dietary habits of subjects}

Table (3) indicates that there were statistically significant differences between controlled epileptics and uncontrolled epileptics in appetite, the presence of unhealthy foods in the home, and eating takeaway foods. The appetite was higher (30\%) in controlled epileptics than in uncontrolled epileptics $(12 \%)$. As a result, having extra meals or snacks was more obvious in controlled patients (15\% and $77.5 \%$, respectively) than in uncontrolled patients ( $6 \%$ and $71.1 \%$, respectively). As for the presence of unhealthy foods in the home as well as eating takeaway foods, they were more prevalent among uncontrolled patients $(22.5 \%$ and $20.4 \%$, respectively) than among controlled patients $(15 \%$ and $5 \%$, respectively). In contrast, there were no significant differences between both groups of patients regarding the other dietary habits included in the used questionnaire, despite the high 
prevalence of habits such as having breakfast as a main meal, taking salad at the beginning of the meals, having breakfast, missing meals especially dinner, drinking more water per day, drinking filtered water and eating fried food more than 5 times per week among controlled patients. In the same time, missing breakfast, drinking tap water, eating low salt and low-fat diet were prevalent among uncontrolled group.

Table 3: Comparison between controlled epileptics and uncontrolled epileptics regarding dietary habits

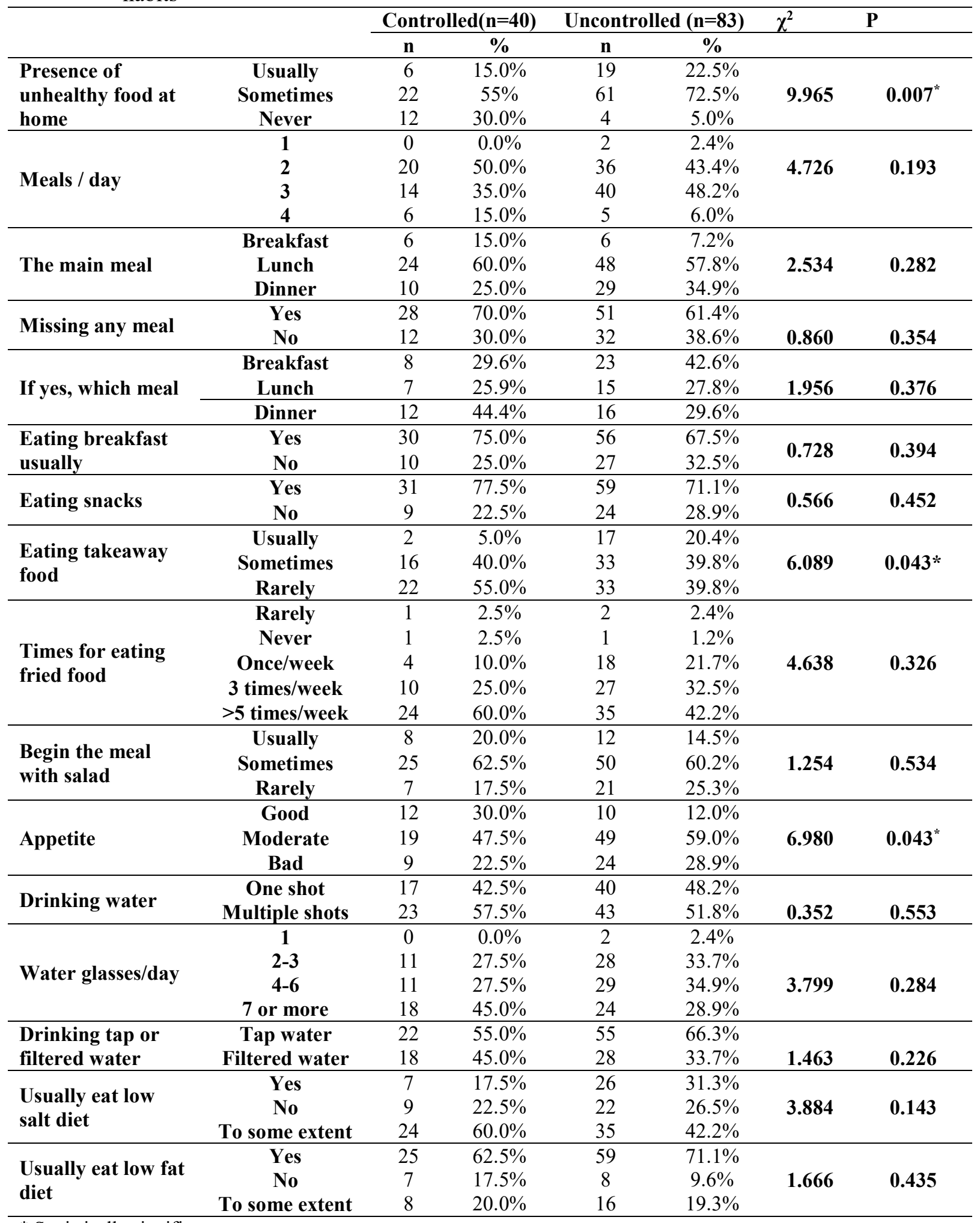

* Statistically significant 
Table (4) shows that there was a reverse and statistically significant correlation between appetite and recurrence of seizures. The higher the appetite, the lower the frequency of attacks. Similarly, there were negative correlations between the frequency of seizures and both frequency of salad eating and the number of glasses of water/day. In contrast, there were positive and statistically significant correlations between frequency of seizure attacks and eating unhealthy food, frequency of fast food eating and consumption of sugar.

Table 4: Correlation between the dietary habits of the study sample and the frequency of seizures

\begin{tabular}{lcc}
\hline Correlation & & Frequency of seizures \\
\hline & $\mathbf{r}$ & -0.374 \\
& $\mathbf{P}$ & $0.001^{*}$ \\
\hline \multirow{2}{*}{ Availability of unhealthy food } & $\mathbf{r}$ & 0.639 \\
& $\mathbf{P}$ & $0.001^{*}$ \\
\hline \multirow{2}{*}{ Frequency of salad eating } & $\mathbf{r}$ & -0.500 \\
& $\mathbf{P}$ & $0.001^{*}$ \\
\hline \multirow{2}{*}{ Fast food eating frequency } & $\mathbf{r}$ & 0.354 \\
& $\mathbf{P}$ & $0.001^{*}$ \\
\hline \multirow{2}{*}{ Number of teaspoons-full sugar } & $\mathbf{P}$ & 0.470 \\
& $\mathbf{P}$ & $0.001^{*}$ \\
\hline \multirow{2}{*}{ Number of glasses of water/day } & $\mathbf{P}$ & -0.281 \\
& $\mathbf{P}$ & $0.002^{*}$ \\
\hline
\end{tabular}

* Statistically significant

\section{Discussion}

Several factors predispose individuals with epilepsy to chronic diseases. Some irregularities in the dietary habits, socioeconomic status (SES) of the adult epileptic population have been identified over time, but there is limited knowledge in this area, motivating further research. Therefore, the aim of this study was to evaluate patients with epilepsy in terms of dietary style and SES and correlate these factors with the disease control. Results indicated statistically significant differences between subjects with controlled epilepsy and uncontrolled epilepsy in both education and socioeconomic levels. The level of education was higher in the group with controlled epilepsy than the uncontrolled group. In line with this finding, Hesdorffer et al., (2005) concluded that low SES, indexed by low education or lack of home ownership, was a risk factor for epilepsy in adults, but not in children.

A prospective study, using a composite measure of SES, concluded that low SES is a risk factor for the development of epilepsy (Heaney et al., 2002). In the same time, low SES patients had consistently higher use of the hospital emergency room and more visits to a general practitioner. They also had a greater likelihood of having uncontrolled seizures, drug-related side effects, to be stigmatized, and having a lower overall quality of life (Begley et al., 2011).

There are clear correlations between epilepsy prevalence and indicators of socioeconomic deprivation on a population basis. Education and employment are the areas with the greatest disparity (Steer et al., 2014). People with epilepsy are more likely to live in socially and economically deprived areas and to be educationally disadvantaged (Kokkonen et al., 1997; Hesodorffer et al., 2005). This relationship, which is common to chronic physical conditions and psychiatric ill health, is exaggerated in epilepsy. People with epilepsy are ineligible to join certain professions and are explicitly and implicitly discriminated against in the workplace. Although some people with epilepsy also have comorbid learning difficulties, epilepsy itself, repeated hospitalization, and antiepileptic medication can impede educational attainment (Heaney et al., 2002). Contrary to the present findings, an incident case-control study found no difference in SES between cases and controls (Forsgren and Nystrom, 1990).

The present findings also confirmed no statistically significant differences between controlled 
epileptics and uncontrolled epileptics in age mean, gender, marital status, having offspring, and occupation. However, most of the participants in the uncontrolled group were females, married, and unemployed. In agreement, Tlusta et al., (2009) did not find any association with gender, age at onset of epilepsy, and systemic comorbidity.

Present findings related to dietary habits indicated a reverse and statistically significant correlation between appetite and recurrence of seizures. Increasing appetite and hence weight gain may be side effects of a number of medications used to treat epilepsy like valproic acid, pregabalin, gabapentin, and carbamazepine (Luef et al., 2003; Ikeda et al., 2018; Fantinati et al., 2020; Lampl et al., 1991).

Like appetite, there were negative correlations between the frequency of seizures and both frequency of salad eating at the beginning of meals and number of glasses of water/day. In general, salad dish is the main source of vitamin $\mathrm{C}$ in daily meals. It is a major antioxidant as well as a neurotransmission regulator (Tome Ada et al., 2010; Harrison and May, 2009). Several animal studies have demonstrated the anticonvulsive effects of vitamin $\mathrm{C}$, which were seen via the reduction of oxidative stress regardless of model systems (Simeone et al., 2014; Gonzalez-Ramirez et al., 2010). However, even with supporting evidence that patients with epilepsy have shown reduced levels of serum vitamin C (Das et al., 2019), no clinical study reporting on the efficacy of vitamin C interventions in epilepsy exists.

The effect of water intake frequency on seizures is mediated by its effect on electrolyte levels in the blood, especially sodium. While hyponatremia is often the cause of seizures or status epilepticus, hypernatremia is more likely to be the consequence of convulsive seizure activity (especially generalized tonic-clonic seizures). Both hyponatremia and hypernatremia are mainly prevented through drinking a moderate amount of water (Nardone et al., 2016). Although the present findings revealed that the number of water glasses per day is negatively correlated with seizures frequency, the maximum amount used by the study sample did not exceed the optimal range of daily water intake, i.e. 7 or more water glasses per day is not excessive or few amount.

In contrast, the present results demonstrated positive and statistically significant correlations between frequency of seizure attacks and eating unhealthy food, frequency of fast food eating, and consumption of sugar. Undoubtedly, unhealthy and fast foods include various components that trigger diseases including neurological diseases. The most important are being salt, soft and energy drinks, glutamate, aspartame, etc. In harmony with these findings, Elliott et al., (2008) reported that persons with a history of epilepsy in the 2005 CHIS report walk more for transportation, drink more soda, and eat less salad than the no epilepsy population. The adolescent portion of the CHIS found that $66 \%$ of California teens consume soda daily, $48 \%$ consume fast food, and only $25 \%$ eat five or more servings of fruits and vegetables each day. Accordingly, persons with a history of epilepsy may continue some poor dietary habits into adulthood.

Through its hypernatremia effect, excessive salt intake can trigger seizures attack. As for caffeine, found in soft and energy drinks, several case reports have suggested caffeine to trigger seizures in people with epilepsy. Seizures were either found to occur after the intake of unusually high (toxic) caffeine doses or after prolonged periods of caffeine intake (Babu et al., 2011; Mackow et al., 2016). Several food additives have been found to trigger seizures. Among them, mono-sodium glutamate appeared to exacerbate seizures in children (Shovic et al., 1997). Moreover, Grand mal seizures have occurred after consumption of aspartame by people who had no prior history of epilepsy (Walton, 1986).

Increased sugar intake is the direct dietary risk factor of hyperglycemia Clinical studies showed that adults with hyperglycemia have an increased predisposition to experiencing seizures. Experimental studies, both in vivo and in vitro, suggest that a threshold glucose concentration is necessary to support synaptic transmission. Conversely, it appears that elevated extracellular glucose is associated with neuronal hyperexcitability, indicating that glucose balance is necessary for normal neurotransmission. The importance of glucose balance has been identified in studies demonstrating that hyperglycemia exacerbates ischemia-induced brain damage, whereas fasting-induced hypoglycemia protects against this neurotoxicity (Stafstrom, 2003).

\section{Conclusion}

Low SES and bad dietary habits are prevalent among uncontrolled hospitalized epileptic 
patients. Increasing socioeconomic status level and dietary behavior modification are recommended in order to improve the health status of hospitalized patients with epilepsy.

\section{Conflict of Interest}

The authors reported no conflict of interest.

\section{References}

Ahmad, B.S., K.D. Hill, T.J. O'Brien, A. Gorelik, N. Habib, and J.D. Wark, 2012. Falls and fractures in patients chronically treated with antiepileptic drugs. Neurology, 79(2): 145-151. https://doi.org/10.1212/WNL.0b013e31825f0466

Amari, A., L. Dahlquist, E.H. Kossoff, E.P. Vining, W.H. Trescher and K.J. Slifer, 2007. Children with seizures exhibit preferences for foods compatible with the ketogenic diet. Epilepsy and Behavior, 11: 98-104.

Babu, K.M., M.D. Zuckerman, J.K. Cherkes, T.C. Nrcc and J.B. Hack, 2011. First-onset seizure after use of 5-hour. Energy, 27:539-540.

Begley, C., R. Basu, D. Lairson, T. Reynolds, S. Dubinsky, M. Newmark, F. Barnwell, A. Hauser and D. Hesdorffer, 2011. Socioeconomic status, health care use, and outcomes: persistence of disparities over time. Epilepsia, 52:957-964.

Begley, C. E., and T.L. Durgin, 2015. The direct cost of epilepsy in the United States: A systematic review of estimates. Epilepsia, 56(9):1376-1387. https://doi.org/10.1111/epi.13084

Castro-Gago, M., L. Pérez-Gay, C. Gómez-Lado, D.E. Castiñeiras-Ramos, S. Otero-Martínez, and S. Rodríguez-Segade, 2011. The influence of valproic acid and carbamazepine treatment on serum biotin and zinc levels and on biotinidase activity. Journal of Child Neurology, 26(12): 1522-1524. https://doi.org/10.1177/0883073811409227

Chen, S.Y., N. Wu, L. Boulanger, and P. Sacco, 2013. Antiepileptic drug treatment patterns and economic burden of commercially-insured patients with refractory epilepsy with partial onset seizures in the United States. Journal of Medical Economics, 16(2): 240-248. https://doi.org/10.3111/13696998.2012.751918

Chowdhury, S., and P.P. Chakraborty, 2017. Universal health coverage - There is more to it than meets the eye. Journal of Family Medicine and Primary Care, 6(2): 169-170. https://doi.org/10.4103/jfmpc.jfmpc

Das, A., M.S. Sarwar, M.S. Hossain, P. Karmakar, M.S. Islam, M.E. Hussain and S. Banik , 2019. Elevated Serum Lipid Peroxidation and Reduced Vitamin $\mathrm{C}$ and Trace Element Concentrations Are Correlated with Epilepsy. Clin EEG Neurosci, 50:63-72.

Dekker, C.F., T.A. van den Hurk and O. van Nieuwenhuizen, 2010. Does a preference for fatty foods prior to commencing treatment with the ketogenic diet predict the efficacy of this diet? Seizure, 19: 421-425.

El-Gilany, A., A. El-Wehady, and M. El-Wasify, 2012. Updating and Validation of the Socioeconomic Status Scale for Health Research in Egypt. Eastern Mediterranean Health Journal, 18(9):962-968.

Elliot, J.O., B. Lu, B. Shneker, C. Charyton and M.J. Layne, 2009. Comorbidity, health screenening, and quality of life among persons with a history of epilepsy. Epilepsy and Behavior, 14:125129.

Elliott, J.O. , B. Lu, J.L. Moore, J.W. McAuley and L. Long, 2008. Exercise, diet, health behaviors, and risk factors among persons with epilepsy based on the California Health Interview Survey, 2005. Epilepsy behaves, 13:307-315.

Fantinati, M., J. Trnka, A. Signor, S. Dumond, G. Jourdan , P. Verwaerde and N. Priymenko, 2020. Appetite-stimulating effect of gabapentin vs mirtazapine in healthy cats post-ovariectomy. J. Feline Med. Surg., 22:1176-1183.

Farghaly, W.M., M.A. Abd Elhamed, E.M. Hassan, W.T. Soliman, M.A. Yhia, and N.A. Hamdy, 2018. Prevalence of childhood and adolescence epilepsy in Upper Egypt (desert areas). Egyptian Journal of Neurology, Psychiatry and Neurosurgery, 54(1): 1-7. https://doi.org/10.1186/s41983-018-0032-0 
Fernandez, R.deA., C. Corrêa, M.M. Bianchin, and I.D.S. Perry, 2015. Perfil antropométrico e ingesta nutricional en pacientes con epilepsia. Nutricion Hospitalaria, 32(2): 817-822.

https://doi.org/10.3305/nh.2015.32.2.9205

Forsgren, L. and L. Nystrom 1990. An incident case-referent study of epileptic seizures in adults. Epilepsy Res., 6:66-81.

Frigerio, R., A. Elbaz, K.R. Sanft, B.J. Peterson, J.H. Bower, J.E. Ahlskog, B.R. Grossardt, M. de Andrade, D.M. Maraganore and W.A. Rocca, 2005. Education and occupations preceding Parkinson disease: a population-based case-control study. Neurology, 65:1575-1583.

Gonzalez-Ramirez, M., L.I. Razo-Juarez, J.L. Sauer-Ramirez, M.E. Gonzalez-Trujano, H. SalgadoCeballos and S. Orozco-Suarez, 2010. Anticonvulsive effect of vitamin C on pentylenetetrazol-induced seizures in immature rats. Pharmacol Biochem Behav., 97:267272.

Heaney, D.C., B.K. MacDonald, A. Everitt, S. Stevenson, G.S. Leonardi, P. Wilkinson and J.W. Sander, 2002. Socioeconomic variation in incidence of epilepsy: prospective community based study in south east England. BMJ ., 325:1013-1016.

Hesdorffer, D.C., H. Tian, K. Anand, W. Allen Hauser, P. Ludvigsson, E. Olafsson and O. Kjartansson, 2005. Socioeconomic status is a risk factor for epilepsy in Icelandic adults but not in children. Epilepsia., 46:1297-1303.

Ikeda, H., N. Yonemochi , C. Ardianto, L. Yang and J. Kamei, 2018. Pregabalin increases food intake through dopaminergic systems in the hypothalamus. Brain Res., 1701:219-226.

Kokkonen, J., E.R. Kokkonen, A.L. Saukkonen and P. Pennanen, 1997. Psychological outcome of young adults with epilepsy in childhood. J Neurol Neurosurg Psychiatry, 62:265-268.

Kobow, K., and I. Blümcke, 2018. Epigenetics in epilepsy. Neuroscience Letters, 667, 40-46. https://doi.org/10.1016/j.neulet.2017.01.012

Kutlu, A., and S. Mülayim, 2016. Psychiatric Comorbidities and Quality of Life in Epilepsy. In Epileptology - The Modern State of Science. InTech. https://doi.org/10.5772/64880

Lampl, Y., Y. Eshel, A. Rapaport and I. Sarova-Pinhas, 1991.Weight gain, increased appetite, and excessive food intake induced by carbamazepine. Clin. Neuropharmacol, 14:251-255.

Long, P.J., and B. Shannon, 1983. Focus on Nutrition; Prentice-Hall, Inc.

Luef, G.J., M. Lechleitner, G. Bauer, E. Trinka and P. Hengster, 2003. Valproic acid modulates islet cell insulin secretion: a possible mechanism of weight gain in epilepsy patients. Epilepsy Res., 55:53-58.

Mackow, M.J., B. Krishnan, W.E. Bingaman, I.M. Najm, A.V. Alexopoulos and D.R. Nair, 2016. Increased caffeine intake leads to worsening of electrocorticographic epileptiform discharges as recorded with a responsive neurostimulation device. Clin. Neurophysiol., 127: 2341-2342.

Nardone, R., F. Brigo and E. Trinka, 2016. Acute symptomatic seizures caused by electrolyte disturbances. J. Clin. Neurol., 12: 21-33.

Organization, W.H., 2019. Epilepsy Fact sheets. https://www.who.int/news-room/factsheets/detail/epilepsy

Olson, L., M. Lara and M. Frintner 2004. Measuring health status and quality of life for US children: Relationship to race, ethnicity, and income status. Ambulatory Pediatrics, 4:377-386.

Prognosis, I., 1993. Guidelines for epidemiologic studies on epilepsy. Epilepsia, 34: 592-596.

Reis, F., B. Sá-Moura, D. Guardado, P. Couceiro, L. Catarino, A. Mota-Pinto, M.T. Veríssimo, A.M. Teixeira, P.L. Ferreira, M.P. Lima, F. Palavra, L. Rama, L. Santos, R.A. van der Heijden, C.E. Gonçalves, A. Cunha, and J.O. Malva, 2019. Development of a Healthy Lifestyle Assessment Toolkit for the General Public. Frontiers in Medicine, 6. https://doi.org/10.3389/fmed.00134

Shovic, A., R.D. Bart and A.M. Stalcup 1997. 'We think your son has Lennox-Gastaut syndrome' - a case study of monosodium glutamate's possible effect on a child. J. Am. Diet. Assoc., 97:793794

Simeone, K.A., S.A. Matthews, K.K. Samson and T.A. Simeone, 2014. Targeting deficiencies in mitochondrial respiratory complex I and functional uncoupling exerts anti-seizure effects in a genetic model of temporal lobe epilepsy and in a model of acute temporal lobe seizures. Exp. Neurol., 251:84-90. 
Soltani, D., M. Ghaffar Pour, A. Tafakhori, P. Sarraf, and S. Bitarafan, 2016. Nutritional aspects of treatment in epileptic patients. Iranian Journal of Child Neurology, 10(3):1-12. https://doi.org/10.22037/ijcn.v10i3.9224

Stafstrom, C.E., 2003. Hyperglycemia lowers seizure threshold. Epilepsy Currents, 3:148-149.

Steer, S., W.O. Pickrell, M.P. Kerr and R.H. Thomas 2014. Epilepsy prevalence and socioeconomic deprivation in England Epilepsia, 55:1634-1641.

Surges, R., and J.W. Sander, 2012. Sudden unexpected death in epilepsy: Mechanisms, prevalence, and prevention. Current Opinion in Neurology, 25(2): 201-207. https://doi.org/10.1097/WCO.0b013e3283506714

Thompson, S.K., 2012. Sampling, $3^{\text {rd }}$ edition. John Wiley and Sons, Inc.

Tlusta, E., J. Zarubova, J. Simko, H. Hojdikova, S. SamSalek and J. Vlcek, 2009. Clinical and demographic characteristics predicting QOL in patients with epilepsy in the Czech Republic: How this can influence practice. Seizure., 18:85-89.

Walton, R.G., 1986. Seizure and mania after high intake of aspartame. Psychosomatics, 27: 218-220.

Zhou, D., and X. Li, 2020. Epilepsy EEG Signal Classification Algorithm Based on Improved RBF. Frontiers in Neuroscience, 14. https://doi.org/10.3389/fnins.2020.00606. 